\title{
A Phase II Study of Erlotinib and Bevacizumab in Patients with Recurrent or Metastatic Squamous Cell Carcinoma of the Head and Neck
}

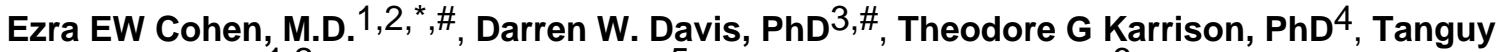 \\ Y. Seiwert, M.D. ${ }^{1,2}$, Stuart J. Wong, M.D. ${ }^{5}$, Sreenivasa Nattam, M.D. ${ }^{6}$, Mark F. Kozloff, M.D. \\ 7, Joseph I. Clark, M.D. ${ }^{8}$, Duen-Hwa Yan, PhD ${ }^{3}$, Wen Liu, M.D. ${ }^{3}$, Carolyn Pierce, B.A. ${ }^{1}$, Janet \\ E Dancey, M.D. ${ }^{9}$, Kerstin Stenson, M.D. ${ }^{10}$, Elizabeth Blair, M.D. ${ }^{10}$, Allison Dekker, B.S.N. ${ }^{1}$, \\ and Everett E Vokes, M.D. $1,2,11, ¥$ \\ ${ }^{1}$ Section of Hematology/Oncology, Department of Medicine, University of Chicago, Chicago, IL \\ 2 University of Chicago Cancer Research Center, Chicago, IL \\ ${ }^{3}$ ApoCell, Inc., Houston, TX \\ ${ }^{4}$ Department of Health Studies, University of Chicago, Chicago, IL \\ ${ }^{5}$ Division of Neoplastic Diseases, Department of Medicine, Medical College of Wisconsin, \\ Milwaukee, WI \\ ${ }^{6}$ Fort Wayne Medical Oncology/Hematology, Fort Wayne, IN \\ 7 Ingalls Hospital, Harvey, IL \\ 8 Loyola University Chicago, Maywood, IL \\ 9 Investigational Drug Branch, Cancer Therapy Evaluation Program, Division of Cancer Treatment \\ and Diagnosis, National Cancer Institute, Rockville, MD \\ 10 Department of Surgery, University of Chicago, Chicago, IL \\ ${ }^{11}$ Department of Radiation and Cellular Oncology, University of Chicago, Chicago, IL
}

\begin{abstract}
Background-The epidermal growth factor receptor (EGFR) is a validated target in squamous cell carcinoma of the head and neck but in patients with recurrent or metastatic disease, EGFR targeting agents have displayed modest efficacy. Vascular endothelial growth factor (VEGF) mediated
\end{abstract}

\footnotetext{
*Corresponding author: Ezra EW Cohen, 5841 South Maryland Avenue, MC2115, Chicago, IL, 60637,

ecohen@medicine.bsd.uchicago.edu.

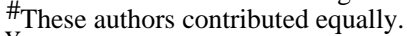

${ }^{¥}$ Indicates full professor.

The authors declared no conflicts of interest.

Contributors: EEWC, DWD, TGK, DHY, WL, JED, EB, and EEV were responsible for the conception and design of the study; EEWC, SJW, SN, MFK, JIC, KS, EB, and EEV were responsible for provision of study material or patients; EEWC, CP, and AD contributed to the collection and assembly of data; EEWC, DWD, TGK, TYS, and EEV were responsible for data analysis and interpretation; EEWC, DWD, TGK, TYS, SJW, JIC, DHY, JED, EB, and EEV were responsible for writing the manuscript.; and JED was responsible for regulatory oversight.

Publisher's Disclaimer: This is a PDF file of an unedited manuscript that has been accepted for publication. As a service to our customers we are providing this early version of the manuscript. The manuscript will undergo copyediting, typesetting, and review of the resulting proof before it is published in its final citable form. Please note that during the production process errors may be discovered which could affect the content, and all legal disclaimers that apply to the journal pertain.
} 
angiogenesis has been implicated as a mechanism of resistance to anti-EGFR therapy. This study combined an EGFR inhibitor, erlotinib, with an anti-VEGF antibody, bevacizumab.

Methods-This multi-institutional phase I/II study enrolled patients with recurrent or metastatic squamous cell carcinoma of the head and neck to receive erlotinib (150 mg daily) and bevacizumab in escalating dose cohorts. The primary objectives in the phase I and II portions, respectively, were to determine the maximum tolerated dose and dose-limiting toxicity of bevacizumab when administered with erlotinib and to determine the objective response rate and time to disease progression. Pre-treatment serum and tissues were collected and analyzed by Enzyme-Linked ImmunoSorbent Assay and immunofluorescence quantitative laser analysis, respectively. This study was registered with ClinicalTrials.gov, number NCT00055913.

Findings-The phase I portion enrolled 10 subjects in three successive cohorts without doselimiting toxicity observed. An additional 46 subjects were enrolled at the phase II dose (bevacizumab $15 \mathrm{mg} / \mathrm{kg}$ every 3 weeks). The most common toxicities of any grade were rash and diarrhea (41 and 16 of 48 subjects, respectively). Three patients experienced serious bleeding events. The observed response rate was $15 \%$ with 4 complete responses (CR) allowing rejection of the null hypothesis. The median overall and progression-free survival (PFS) durations were 7.1 (95\% Confidence Interval: 5.7 to 9.0 ) and 4.1 (95\% Confidence Interval: 2.8 to 4.4$)$ months, respectively. Higher ratios of phosphorylated over total VEGF receptor-2 and EGFR in pre-treatment biopsies were associated with CR ( 0.7043 vs. $0.3857, \mathrm{p}=0.036$ and 0.949 vs. $0.332, \mathrm{p}=0.036$, respectively) and tumor shrinkage ( $\mathrm{p}=0.007$ and $\mathrm{p}=0.008$, respectively) in a subset of 11 subjects with available tissue.

Interpretation-The combination of erlotinib and bevacizumab is well tolerated in recurrent or metastatic squamous cell carcinoma of the head and neck. Some patients appear to derive a sustained benefit and complete responses were associated with expression of putative targets in pre-treatment tumor tissue.

\section{Introduction}

Squamous cell carcinoma of the head and neck (squamous cell carcinoma of the head and neck) is the $6^{\text {th }}$ most common malignancy with a worldwide incidence of approximately 500,000 (1). Recurrent or metastatic (recurrent or metastatic) disease will occur in 50\% of patients who can be offered palliative chemotherapy but the majority will die within 1 year(2). The epidermal growth factor receptor (EGFR) is almost universally expressed in squamous cell carcinoma of the head and neck and higher expression has been linked with poor outcome.

Recently, a phase III study tested whether adding an anti-EGFR antibody, cetuximab, to platin/ 5-fluorouracil chemotherapy would improve survival in patients with recurrent or metastatic disease(3). The results of the study significantly favored the experimental arm with respect to response rate (36 vs. $20 \%$ ) and median overall survival (10.1 vs. 7.4 months) demonstrating the utility of administering cetuximab in combination with cytotoxic chemotherapy.

However response rates to EGFR inhibitors as single agents are modest and mechanisms underlying resistance elusive(4). In preclinical models upregulation of vascular endothelial growth factor (VEGF) has been implicated in resistance to EGFR inhibition(5-7). In fact, administering EGFR inhibitors in combination with anit-angiogenic agents has demonstrated additive cytotoxicity in these models.

The current study, therefore, sought to assess the feasibility and tolerability of escalating doses of an anti-VEGF monoclonal antibody, bevacizumab, administered concurrently with an EGFR small molecule tyrosine kinase inhibitor (TKI), erlotinib. Upon reaching the planned dose, the combination was evaluated in a phase II cohort. Pre-treatment serum and tissue was obtained from subjects to evaluate potential predictive markers. 


\section{Methods}

\section{Patient Selection and Treatment}

Major eligibility criteria included pathologic and Response Evaluation Criteria in Solid Tumors (RECIST) (8) defined measurable evidence of recurrent or metastatic squamous cell carcinoma, age $\geq 18$ years, Eastern Cooperative Oncology Group performance status $\leq 2$, International Normalized Ratio of prothrombin time $<1.5$, leukocyte count $\geq 3,000 / \mu 1$, absolute neutrophil count $\geq 1,500 / \mu 1$, platelet count $\geq 100,000 / \mu \mathrm{l}$, total serum bilirubin within institutional limits, AST (SGOT) and ALT (SGPT) $\leqq 2.5$ times institutional upper limit of normal, and serum creatinine within institutional limits. Patients were excluded if there was evidence of brain metastasis; more than one prior regimen for recurrent or metastatic disease; prior anti-EGFR or VEGF-based therapy; tumor encasing or deemed to be in close proximity to a major blood vessel; history of a bleeding diathesis, deep venous thrombosis, clinically significant cardiovascular disease, non-healing wounds, major surgery within 4 weeks, uncontrolled hypertension, or significant ophthalmologic abnormalities; or chronic use of aspirin ( $\geq 325 \mathrm{mg} / \mathrm{d}$ ), non-steroidal anti-inflammatory drugs, therapeutic warfarin, or heparins. The study was approved by each participating site's Institutional Review Board and all subjects were required to understand and sign the approved written informed consent document.

In phase I bevacizumab (Genentech, South San Francisco, US) was administered intravenously every three weeks and dose escalated in three successive cohorts of 5,10 , and $15 \mathrm{mg} / \mathrm{kg}$. Erlotinib (OSI Pharmaceuticals, Melville, US) was administered orally at $150 \mathrm{mg}$ every day without escalation in all cohorts. Dose escalation and accrual to next dose cohort proceeded using a " $3+3$ " design(9). Maximum administered doses were used in phase II.

Dose limiting toxicity (DLT) was assessed in cycle 1 and defined as grade $\geq 3$ toxicity except fatigue; hypertension that was not medically controlled; development of nephrotic syndrome or severe hemorrhage; or inability, due to any toxicity, to complete a total of one cycle, or delay of the start of the next cycle for greater than 7 days, or greater than 7 days delay in erlotinib administration. National Cancer Institute Common Terminology Criteria for Adverse Events version 2.0 was used to grade toxicity.

Patients in the phase II portion were randomized to one of two arms ("A" and "B") for cycle 1 only to assess molecular endpoints related to erlotinib and bevacizumab administration. In both arms patients received erlotinib daily without interruption. In arm A bevacizumab was added on day 15 and in arm B bevacizumab was started on day 1. Bevacizumab was administered on day 1 of all subsequent cycles. Disease was assessed according to RECIST every 6 weeks.

\section{Tumor and Serum Analysis}

Tumor biopsies were performed using a 14-guage biopsy needle, instantly frozen, and stored at $-80^{\circ} \mathrm{C}$ as previously described(10). Enzyme-Linked ImmunoSorbent Assay on serum Transforming Growth Factor-alpha (TGF- $\alpha$ ) and VEGF was performed in triplicate as previously described(11).

Antibodies against human phosphorylated (p) VEGFR2 (PC460, Calbiochem;1:1,000), VEGFR2 (BD Pharmingen;1:100), pEGFR (Y1173, Santa Cruz Biotechnology;1:100), EGFR (1005, Santa Cruz;1:100), pERK (Calbiochem;1:100), ERK (Calbiochem1:100), pAKT (Calbiochem Cat\# 1240011:100), AKT (Cell Signaling Cat\# 2966;1:100) and CD31 (DakoCytomation 1:100) were incubated with the rehydrated slides as previously described (12). 
Quantification of the protein expression was determined by laser scanning cytometry (LSC) analysis which obtains two- and three-color mean fluorescence intensity (MFI) information as previously described $(12,13)$. Cell nuclei were contoured using the red fluorescence (propidium iodide) detector. CD31-positive vessels were detected by Cy5 fluorescence using the long red fluorescence detector, and -biomarker positive events, i.e., phosphorylated and total VEGFR-2, EGFR, ERK, and AKT, were detected using the green detector. All cells within the tumor as assessed by hematoxylin and eosin stain that did were CD-31 positive or negative were considered endothelial cells (EC) or tumor cells (TC), respectively.

\section{Statistical considerations}

The phase II portion utilized a two-stage design to test the null hypothesis that the response rate is $\leq 5 \%$ and the percentage of patients not progressing within two months is $\leq 30 \%$ against the alternative that either is greater $(14,15)$. RECIST criteria(8) were used to determine response with measurements obtained every two cycles (six weeks) using either conventional CT or MRI. The design called for 22 patients to be enrolled in the first stage. If fewer than 2 responses and more than 14 patients progressed, the study would be halted for lack of efficacy. Otherwise an additional 24 patients were to be enrolled for a total of 46. If 6 or more responses were observed or fewer than 29 patients progressed within two months, the treatment would be considered worthy of further study, whereas if 5 or fewer responses were observed and 29 or more patients progressed within two months, the treatment would not be deemed worthy of further investigation. At $\alpha$-level of approximately 0.10 , this design has $90 \%$ power if the true response rate is $20 \%$ and the stable disease rate is $10 \%$ or if the true response rate is $5 \%$ and the stable disease rate is $45 \%$.

Overall survival (OS) is defined as the time from entry into the trial until death from any cause. Patients who had not died were censored as of the date last known alive. Progression-free survival (PFS) is defined as the time from entry into the trial until disease progression or death from any cause. Patients remaining alive without disease progression were censored as of the date last known progression free. These rates were estimated by the Kaplan-Meier(16) method and comparisons were made via the log-rank test. Patients alive without recurrence were censored as of the date of the last negative exam. Post-hoc, exploratory analyses were performed to examine the effects of potential prognostic variables on PFS and OS using the Cox(17) regression model. Univariate models were first fit to evaluate the effects of sex, race, prior systemic chemotherapy and other baseline variables on OS and PFS. Multivariable Cox regression(17) analyses were then performed, followed by analysis of the prognostic significance of the occurrence of skin rash and diarrhea. For these analyses, rash and diarrhea were modeled as time-dependent covariates (step functions) taking the value 0 prior to occurrence of the toxicity and 1 afterwards. For patients never experiencing the toxicity the covariate value remains 0 throughout.

All laboratory analyses in this study were performed blinded to patient clinical data. Pretreatment biomarker expressions were compared between responders and non-responders using exact permutation tests. The prognostic value of biomarkers for PFS and OS was assessed using the Cox model. All $\mathrm{p}$-values are two-sided and $\mathrm{p}<0.05$ was considered statistically significant.

\section{Role of the Funding Source}

The sponsor had no role in the study design; collection, analysis, or interpretation of the data; or writing of the manuscript. One author (JED) was employed by the sponsor and contributed to study design and writing of the manuscript. All authors had full access to subject deidentified raw data. The corresponding author had full access to all of the data and the final responsibility to submit for publication. 


\section{Results}

A total of 56 patients were entered onto the study from April 15, 2003 to January 27, 2005, 10 in phase I and 46 in phase II (Figure 1 and Table 1). One subject in the first dose cohort withdrew from study prior to completion of cycle 1 due to a rising serum prostate specific antigen and was not considered evaluable. The first three patients at the highest dose $(15 \mathrm{mg} / \mathrm{kg})$ from the phase I portion of the trial were included in the phase II evaluation. Conversely, the first three patients in the phase II portion were used to confirm that $15 \mathrm{mg} / \mathrm{kg}$ was the maximum tolerable dose. One subject in the phase II study was deemed non-evaluable due to missing baseline CT scans, but two extra patients were accrued beyond the protocol-stipulated 46, leaving a total of 48 patients for the phase II evaluation. The database was locked on October 1, 2007. Twenty pre-treatment tumor biopsies were obtained; 7 lacked TC or were inadequate for analysis and 1 subject was non-evaluable due to early withdraw from study.

No DLT were observed as defined in the phase I portion. Therefore bevacizumab, $15 \mathrm{mg} / \mathrm{kg}$, with erlotinib, $150 \mathrm{mg}$ every day, was administered in the subsequent phase II portion. Grade 3 or 4 toxicities attributed to therapy occurred in 5 of 10 patients after cycle 1 (one grade 4 hemorrhage during cycle 5 , one grade 4 anorexia with grade 3 oesophagitis during cycle 6 , and one grade 3 diarrhea, pruritis, and lymphopenia). Rash was the most common toxicity observed developing in 8 of 10 patients and was independent of dose level. One partial response was observed at dose level 1 .

There were 48 evaluable patients for the phase II portion. Among the first 22 first-stage patients enrolled there were 3 responders and 7 patients with stable disease for $\geq$ two months; hence the study proceeded to stage 2 . Among the first 46 patients enrolled, 7 were responders, 14 had stable disease (SD) for $\geq$ two months, and 25 had early progressive disease (PD) or did not complete first response assessment. Hence pre-specified criteria were met to declare the combination sufficiently active for further study. Among the 48 subjects, best observed response included 7 [15\%, 95\% confidence interval (CI) 6-28\%] CR or PR and 15 (31\%) SD. Among the four complete responders, duration of response was 2.5 months, $>17$ months (observation censored), unknown (patient lost to follow-up), and 5 months, respectively. Among three partial responders, the duration of response was 1.5 months, 3 months, and >21 months (observation censored), respectively. The mean number of cycles administered was 4.6 (range 1-48) and the mean treatment duration was 137 days (range 33-1015 days) with one patient still on treatment after 33 months.

The median OS time was 7.1 months (95\% CI: 5.7 to 9.0) with 15 subjects surviving 1 year. The median PFS time was 4.1 months (95\% CI: 2.8 to 4.4). Kaplan-Meier OS and PFS curves are shown in Figure 2. Prolonged PFS, lasting 24 months or more, was observed in 3 subjects, two of whom received erlotinib/bevacizumab as their first treatment for recurrent or metastatic squamous cell carcinoma of the head and neck with all demonstrating responses (2 CR and 1 PR).

The most common drug related toxicities were rash, diarrhea, fatigue, stomatitis, anorexia, and laboratory abnormalities (Table 2). Thirteen subjects had their treatment delayed at some point, but only one patient required a dose reduction (erlotinib reduced to $100 \mathrm{mg}$ every day due to rash). Four subjects discontinued therapy due to toxicity -1 deep venous thrombosis, 2 serious hemorrhagic events, and 1 hypoalbuminemia.

One of the serious hemorrhagic events was fatal and on autopsy it was ascertained to be laryngeal in origin but not at a site of active disease. The other hemorrhagic event occurred in a site of disease involvement in the floor of mouth. The only common element between the hemorrhagic events observed in phase I and II portions was that all subjects received prior radiotherapy to the site; however, 42 of the 56 patients enrolled had prior radiotherapy. 
There was no statistically significant association between receipt of prior systemic chemotherapy for recurrent or metastatic disease and best response $(\mathrm{p}=0.64)$, however, both OS and PFS rates were significantly higher in first-line patients (Figure 3). For OS, a Cox regression model yielded a hazard ratio (HR) of 2.45 (95\% CI: 1.32 to $4.56, \mathrm{p}=0.0046$ ) for patients with prior therapy compared to those without. For PFS, the HR was 2.40 (95\% CI: 1.28 to $4.50, \mathrm{p}=0.0062$ ).

There was no statistically significant association between treatment arm and best response, PFS, or OS.

Univariate Cox proportional hazards regression models were performed to screen for additional prognostic factors including sex, race, disease type (local/regional recurrence, distant metastasis, or both), performance status, age, and prior therapy. Significant prognostic variables were sex and disease type for OS and disease type for PFS (Table 3).

Multivariate analyses were performed including performance status, gender, disease type, and first vs. second-line status in the model (Table 4). Significant prognostic factors were secondline status for OS ( $\mathrm{p}=0.020)$ and disease type and second-line status for PFS ( $\mathrm{p}=0.016$ and 0.037 , respectively). Patients with prior therapy were at approximately two-fold greater risk than first-line patients for both endpoints. The hazard rate for disease progression/death was nearly three-fold higher among patients with both locally advanced and metastatic disease compared to those with only locally advanced cancer.

Following the multivariate analysis the association between the occurrence of rash [grade 2 or higher (23 cases)] and diarrhea [any grade (16 cases)] with outcomes was examined. Since the occurrence of rash and diarrhea are "post-baseline" variables, these analyses should be interpreted cautiously(18). Multivariate Cox regression models for OS and PFS were fit including these variables as well as first vs. second-line status and disease type (Table 5). Time to event was measured from entry into the study. Occurrence of diarrhea was associated with improved (hazard ratio less than 1) OS ( $\mathrm{p}=0.0023)$ but no significant association was found for rash or when PFS was the endpoint. If diarrhea occurring only during cycle 1 is considered, the association with OS is no longer statistically significant (HR $=0.74,95 \% \mathrm{CI}$ : 0.35 to 1.54 , $\mathrm{p}=0.41$ ).

To identify biomarkers of response, we undertook exploratory analysis of putative targets of erlotinib and bevacizumab by quantifying their expression in TC and tumor-associated EC compartments. Best response among subjects from whom tumor tissue was obtained included 2 with CR and 9 with non-CR ( 1 with PR, 3 with SD, and 5 with PD). Analysis revealed little difference in pVEGFR2 expression between CR and non-CR patients (Table 6). However, the non-CR patients expressed 2-fold higher total VEGFR2 than the CR patients (Table 6, Figure 4A). Thus, the TC pVEGFR2/VEGFR2 ratio in CR patients was significantly higher than the non-CR patients ( 0.7043 vs. $0.3857, \mathrm{p}=0.036$ ) (Table 6, Figure $4 \mathrm{C}$ ). Analysis of tumorassociated EC expression of pVEGFR2/VEGFR2 ratio revealed no significant difference between CR and non-CR patients (Table 6).

We also investigated whether elevated expression of pEGFR/EGFR favored a better clinical outcome. Overall, CR patients had higher expression of both pEGFR and EGFR compared to non-CR patients (Table 6). The results are similar if the two CR patients are compared only to patients who developed early progressive disease $(\mathrm{n}=5)$ (data not shown). Tumor-associated EC expression of pEGFR/EGFR ratio were significantly higher in patients with a CR compared to non-CR patients ( 0.949 vs. $0.332, \mathrm{p}=0.036$ ) (Table 6; Figure 4B, C). TC pEGFR/EGFR ratio were also higher in $\mathrm{CR}$ patients compared to non-CR patients, but the difference did not reach statistical significance. Analysis of additional mechanism biomarkers including 
phosphorylated and total ERK and AKT revealed no significant association with CR (Table $6)$.

Since pVEGFR2/VEGFR2 and EC pEGFR/EGFR ratios were associated with CR, we investigated whether pre-treatment expression correlated with maximal reduction in tumor size during therapy measured on a continuous scale. Interestingly, higher TC pVEGFR2/VEGFR2 and EC pEGFR/EGFR correlated significantly with change in tumor size $(r=-0.76, p=0.007$ and $\mathrm{r}=-0.75, \mathrm{p}=0.008$, respectively) (Figure 5).

We next investigated whether the pVEGFR2/VEGFR2 and EC pEGFR/EGFR ratios were predictive of survival using the Cox regression model. Analysis of pVEGFR2/VEGFR2 did not reveal a statistically significant association with PFS (Figure 6A, $\mathrm{p}=0.32$ ) or OS $(\mathrm{p}=0.62)$. In addition, OS and PFS (Figure 6B) results for EC pEGFR/EGFR were non-significant $(\mathrm{p}=0.26$ and $\mathrm{p}=0.12$, respectively).

Since VEGF and TGF $\alpha$ are primary ligands for VEGFR2 and EGFR, respectively, we ascertained whether their concentration in subject sera was associated with outcome. Baseline VEGF and TGF $\alpha$ concentrations were obtained in 28 and 27 subjects, respectively. The median VEGF concentration at baseline was $52.0 \mathrm{pg} / \mathrm{ml}$ (range $0-616.3$ ) while TGF $\alpha$ concentrations were highly variable with a median of $28.9 \mathrm{pg} / \mathrm{ml}$ (range $0-12,000$ ). Baseline VEGF concentrations were not found to be significantly associated with response $(\mathrm{p}=0.43$, exact permutation test), PFS ( $\mathrm{p}=0.42$ ), or OS ( $\mathrm{p}=0.40)$, nor did baseline TGF $\alpha$ concentrations $(\mathrm{p}=0.70, \mathrm{p}=0.41$, and $\mathrm{p}=0.97$, respectively).

\section{Discussion}

To our knowledge, this is the first study to combine an EGFR inhibitor with an antiangiogenic agent in squamous cell carcinoma of the head and neck. Erlotinib and bevacizumab were well tolerated while the observed response rate of $15 \%$ compares favorably with that reported in trials of erlotinib (5\%)(19) or the VEGFR inhibitors SU5416 (5\%)(20) and sorafenib (3-4\%) (21). Preclinical studies and clinical trials in other cancers indicate that the addition of an antiangiogenic drug to an EGFR inhibitor improves efficacy (5-7,22-24). However, this trial was not designed to compare erlotinib with or without bevacizumab and other studies administering single agent EGFR inhibitors have reported single agent response rates of 11$13 \%$ with a possible dose-response relationship $(10,11,25)$. Interestingly, in the present study there appeared to be a subset of patients that had prolonged benefit from the combination. The tumor of one patient, who sustained a durable complete response, was confirmed negative for EGFR gene amplification and tyrosine kinase mutation(26). The finding that markers of activated putative targets of the studied agents, VEGFR2 and EGFR, in pre-treatment tumor biopsies were associated with tumor response raises the possibility of patient selection and warrants further evaluation in prospective trials but must be viewed as preliminary and hypothesis generating.

That high expression of the ratio of phosphorylated- EGFR/EGFR and VEGFR/VEGFR were detected on human tumor EC and TC, respectively, is novel and appears counterintuitive. However, these results are not entirely surprising given that EGFR is expressed on tumorassociated EC $(27,28)$ and anti-EGFR drugs have a direct inhibitory effect on tumor EC proliferation(29). Preclinical studies suggest that in tumor EC from gefitinib-treated mice there is a switch from dependence on EGFR activity to signaling via VEGFR2(30). In addition, recent studies have implicated VEGF/VEGFR in the proliferation(31) and migration(32) of tumor epithelial cells. Furthermore, VEGF increases proliferation of breast cancer cells and is dependent on VEGFR2(33). Therefore, it is plausible that in a subset of metastatic squamous cell carcinoma of the head and neck, expression of VEGFR2 and EGFR on TC and EC, 
respectively, correspond to critical biologic functions in those compartments and when inhibited by specific agents, tumor inhibition is observed.

Notably, when interpreting receptor phosphorylation we employed the ratio of phosphorylated to total protein expression. In fact, phosphorylation or VEGFR2 or EGFR per se was not significantly associated with outcome. This suggests that interpretation of phosphorylated protein expression should be performed in the context of total protein and caution is needed when evaluating the activity of tyrosine kinase (TK) inhibitors using phosphorylated TK alone. Indeed, recent studies have shown that assessment of phosphorylated Platelet Derived Growth Factor Receptor (PDGFR)- $\beta /$ PDGFR $\beta$ ratios following sunitinib treatment in gastrointestinal stromal tumors correlated significantly better with clinical outcome compared to measuring phosphorylation of the receptor alone(34). Any conclusions based on the biomarker studies, however, must be interpreted with caution. Although the findings are scientifically plausible, there remains the possibility that the associations detected are due to chance alone given the large number of markers evaluated. On the other hand, the small sample size limits the power of these analyses.

Specific clinical factors appeared to influence outcome as well. Subjects who were treated as first-line therapy for recurrent or metastatic disease fared better with respect to PFS and OS which likely reflects the prognostic value of prior therapy and should inform future study design. Interestingly, only development of diarrhea was associated with improved survival. Of note, the association between diarrhea and OS is not significant when diarrhea incidence during cycle 1 only is examined.

Three subjects experienced serious bleeding events during therapy for an incidence of 5\% overall ( 3 of 56 patients). Hemorrhagic events have been described during bevacizumab therapy in other cancers including squamous cell carcinoma of the lung and these events could be attributed to therapy. Conversely, patients with recurrent or metastatic squamous cell carcinoma of the head and neck are prone to bleeding events even without therapy due to the anatomic density of vascular structures, proximity of disease to vessels, and prior surgery or radiotherapy. In fact, the rate of serious hemorrhage on other studies enrolling recurrent or metastatic patients administering EGFR inhibitors or chemotherapy was similar $(10,35,36)$. Furthermore, a recent randomized phase II study integrating bevacizumab with chemoradiotherapy in patients with locally advanced disease did not report any bleeding events (37). Nevertheless, the events observed in this study should raise a cautionary note as this combination is further explored in clinical trials.

Overall, erlotinib and bevacizumab proved to be well tolerated. Dose reduction and discontinuation due to toxicity were only required in one and four subjects, respectively, and the overall incidence of grade 3 or greater toxicity was acceptable while the great majority of these events were easily reversible (e.g. mucocutaneous toxicity, fatigue, diarrhea, and anorexia). In this group of patients who are being treated with palliative intent, the tolerability of therapy becomes an important consideration. Thus, although the objective response rate of cetuximab/platin/5-FU or other cytotoxic chemotherapy combinations in patients with recurrent or metastatic disease is likely to be higher than that observed in the current study, dual pathway inhibition of EGFR and angiogenesis potentially offers a feasible alternative.

The observation of durable disease control, complete responses, and the possible identification of a predictive biomarker should prompt further study of this regimen or other EGFR inhibitorantiangiogenic combinations in squamous cell carcinoma of the head and neck. Erlotinib/ bevacizumab combinations are currently being investigated in squamous cell carcinoma of the head and neck and preliminary data were recently presented combining cetuximab and bevacizumab in recurrent or metastatic squamous cell carcinoma of the head and neck 
demonstrating promising efficacy(38). We hypothesize that high pVEGFR2/VEGFR2 and EC pEGFR/EGFR ratios in baseline tumor biopsies predict clinical outcome in patients undergoing erlotinib and bevacizumab therapy. Although these findings are preliminary and exploratory, there appears to be a subset of patients that derives a benefit from this combination and the ability to select them prior to initiating therapy would be invaluable. Recurrent or metastatic squamous cell carcinoma of the head and neck is an almost universally fatal disease. EGFR inhibitors are active but response rates are modest. The addition of bevacizumab represents a potential strategy to improve efficacy and this study adds credibility to that hypothesis.

\section{Acknowledgments}

Funding: National Cancer Institute, National Institutes of Health, Bethesda, MD (grant no. N01-CM-17102) and the University of Chicago Cancer Research Center, Chicago, IL (grant no. P30 CA14599).

The authors wish to acknowledge the contributions of Helen Chen, Ann Mauer, Jerome Winegarden, Leslie Martin, David J. McConkey, Jennifer Lam, and Katherine Nichols.

\section{References}

1. Pisani P, Bray F, Parkin DM. Estimates of the world-wide prevalence of cancer for 25 sites in the adult population. Int J Cancer 2002;97:72-81. [PubMed: 11774246]

2. Ahmed SM, Cohen EE. Treatment of squamous cell carcinoma of the head and neck in the metastatic and refractory settings: advances in chemotherapy and the emergence of small molecule epidermal growth factor receptor kinase inhibitors. Current cancer drug targets 2007;7:666-73. [PubMed: 18045071]

3. Vermorken JB, Mesia R, Rivera F, Remenar E, Kawecki A, Rottey S, et al. Platinum-based chemotherapy plus cetuximab in head and neck cancer. N Engl J Med 2008;359:1116-27. [PubMed: 18784101]

4. Cohen EE. Role of epidermal growth factor receptor pathway-targeted therapy in patients with recurrent and/or metastatic squamous cell carcinoma of the head and neck. J Clin Oncol 2006;24:2659-65. [PubMed: 16763280]

5. Ciardiello F, Bianco R, Damiano V, Fontanini G, Caputo R, Pomatico G, et al. Antiangiogenic and antitumor activity of anti-epidermal growth factor receptor $\mathrm{C} 225$ monoclonal antibody in combination with vascular endothelial growth factor antisense oligonucleotide in human GEO colon cancer cells. Clin Cancer Res 2000;6:3739-47. [PubMed: 10999768]

6. Viloria-Petit A, Crombet T, Jothy S, Hicklin D, Bohlen P, Schlaeppi JM, et al. Acquired resistance to the antitumor effect of epidermal growth factor receptor-blocking antibodies in vivo: a role for altered tumor angiogenesis. Cancer Res 2001;61:5090-101. [PubMed: 11431346]

7. Ciardiello F, Bianco R, Caputo R, Caputo R, Damiano V, Troiani T, et al. Antitumor activity of ZD6474, a vascular endothelial growth factor receptor tyrosine kinase inhibitor, in human cancer cells with acquired resistance to antiepidermal growth factor receptor therapy. Clin Cancer Res 2004;10:78493. [PubMed: 14760102]

8. Therasse P, Arbuck SG, Eisenhauer EA, Wanders J, Kaplan RS, Rubinstein L, et al. New guidelines to evaluate the response to treatment in solid tumors. European Organization for Research and Treatment of Cancer, National Cancer Institute of the United States, National Cancer Institute of Canada J Natl Cancer Inst 2000;92:205-16.

9. Storer BE. Design and analysis of phase I clinical trials. Biometrics 1989;45:925-37. [PubMed: 2790129]

10. Cohen EE, Rosen F, Stadler WM, Recant W, Stenson K, Huo D, et al. Phase II Trial of ZD1839 in Recurrent or Metastatic Squamous Cell Carcinoma of the Head and Neck. J Clin Oncol 2003;21:1980-7. [PubMed: 12743152]

11. Cohen EE, Kane MA, List MA, Brockstein BE, Mehrotra B, Huo D, et al. Phase II trial of gefitinib $250 \mathrm{mg}$ daily in patients with recurrent and/or metastatic squamous cell carcinoma of the head and neck. Clin Cancer Res 2005;11:8418-24. [PubMed: 16322304] 
12. Davis DW, Takamori R, Raut CP, Xiong HQ, Herbst RS, Stadler WM, et al. Pharmacodynamic analysis of target inhibition and endothelial cell death in tumors treated with the vascular endothelial growth factor receptor antagonists SU5416 or SU6668. Clin Cancer Res 2005;11:678-89. [PubMed: 15701856]

13. LoRusso, PM.; Bekele, BN.; Boerner, SA.; Davis, DW.; Evelhoch, JL.; Herbst, RS. Phase I trials today. In: Mendelsohn, J.; Howley, PM.; Israel, MA.; Gray, JW., editors. The molecular basis of cancer. Vol. 3. 2008. p. 553-70.

14. Dent S, Zee B, Dancey J, Hanauske A, Wanders J, Eisenhauer E. Application of a new multinomial phase II stopping rule using response and early progression. J Clin Oncol 2001;19:785-91. [PubMed: 11157032]

15. Zee B, Melnychuk D, Dancey J, Eisenhauer E. Multinomial phase II cancer trials incorporating response and early progression. J Biopharm Stat 1999;9:351-63. [PubMed: 10379698]

16. Kaplan ELMP. Nonparametric estimation from incomplete observations. J Am Stat Assoc 1958;53:457-81.

17. Cox D. Regression models and life tables (with discussion). J R Stat Soc B 1972;26:103-10.

18. Fisher LD, Lin DY. Time-dependent covariates in the Cox proportional-hazards regression model. Annu Rev Public Health 1999;20:145-57. [PubMed: 10352854]

19. Soulieres D, Senzer NN, Vokes EE, Hidalgo M, Agarwala SS, Siu LL. Multicenter Phase II Study of Erlotinib, an Oral Epidermal Growth Factor Receptor Tyrosine Kinase Inhibitor, in Patients With Recurrent or Metastatic Squamous Cell Cancer of the Head and Neck. J Clin Oncol 2004;22:77-85. [PubMed: 14701768]

20. Fury MG, Zahalsky A, Wong R, Venkatraman E, Lis E, Hann L, et al. A Phase II study of SU5416 in patients with advanced or recurrent head and neck cancers. Invest New Drugs 2007;25:165-72. [PubMed: 16983506]

21. Elser C, Siu LL, Winquist E, Agulnik M, Pond GR, Chin SF, et al. Phase II trial of sorafenib in patients with recurrent or metastatic squamous cell carcinoma of the head and neck or nasopharyngeal carcinoma. J Clin Oncol 2007;25:3766-73. [PubMed: 17704426]

22. Herbst RS, O'Neill VJ, Fehrenbacher L, Belani CP, Bonomi PD, Hart L, et al. Phase II study of efficacy and safety of bevacizumab in combination with chemotherapy or erlotinib compared with chemotherapy alone for treatment of recurrent or refractory non small-cell lung cancer. J Clin Oncol 2007;25:4743-50. [PubMed: 17909199]

23. Saltz LB, Lenz HJ, Kindler HL, Hochster HS, Wadler S, Hoff PM, et al. Randomized phase II trial of cetuximab, bevacizumab, and irinotecan compared with cetuximab and bevacizumab alone in irinotecan-refractory colorectal cancer: the BOND-2 study. J Clin Oncol 2007;25:4557-61. [PubMed: 17876013]

24. Prichard CN, Kim S, Yazici YD, Doan DD, Jasser SA, Mandal M, et al. Concurrent cetuximab and bevacizumab therapy in a murine orthotopic model of anaplastic thyroid carcinoma. Laryngoscope 2007;117:674-9. [PubMed: 17429874]

25. Vermorken JB, Trigo J, Hitt R, Koralewski P, Diaz-Rubio E, Rolland F, et al. Open-label, uncontrolled, multicenter phase II study to evaluate the efficacy and toxicity of cetuximab as a single agent in patients with recurrent and/or metastatic squamous cell carcinoma of the head and neck who failed to respond to platinum-based therapy. J Clin Oncol 2007;25:2171-7. [PubMed: 17538161]

26. Cohen EE, Lingen MW, Martin LE, Harris PL, Brannigan BW, Haserlat SM, et al. Response of some head and neck cancers to epidermal growth factor receptor tyrosine kinase inhibitors may be linked to mutation of ERBB2 rather than EGFR. Clin Cancer Res 2005;11:8105-8. [PubMed: 16299242]

27. Kedar D, Baker CH, Killion JJ, Dinney CP, Fidler IJ. Blockade of the epidermal growth factor receptor signaling inhibits angiogenesis leading to regression of human renal cell carcinoma growing orthotopically in nude mice. Clin Cancer Res 2002;8:3592-600. [PubMed: 12429651]

28. Sini P, Wyder L, Schnell C, O'Reilly T, Littlewood A, Brandt R, et al. The antitumor and antiangiogenic activity of vascular endothelial growth factor receptor inhibition is potentiated by ErbB1 blockade. Clin Cancer Res 2005;11:4521-32. [PubMed: 15958638]

29. Amin DN, Hida K, Bielenberg DR, Klagsbrun M. Tumor endothelial cells express epidermal growth factor receptor (EGFR) but not ErbB3 and are responsive to EGF and to EGFR kinase inhibitors. Cancer Res 2006;66:2173-80. [PubMed: 16489018] 
30. Amin DN, Bielenberg DR, Lifshits E, Heymach JV, Klagsbrun M. Targeting EGFR activity in blood vessels is sufficient to inhibit tumor growth and is accompanied by an increase in VEGFR-2 dependence in tumor endothelial cells. Microvasc Res 2008;76:15-22. [PubMed: 18440031]

31. Liang Y, Hyder SM. Proliferation of endothelial and tumor epithelial cells by progestin-induced vascular endothelial growth factor from human breast cancer cells: paracrine and autocrine effects. Endocrinology 2005;146:3632-41. [PubMed: 15845615]

32. Lesslie DP, Summy JM, Parikh NU, Fan F, Trevino JG, Sawyer TK, et al. Vascular endothelial growth factor receptor-1 mediates migration of human colorectal carcinoma cells by activation of Src family kinases. Br J Cancer 2006;94:1710-7. [PubMed: 16685275]

33. Liang Y, Brekken RA, Hyder SM. Vascular endothelial growth factor induces proliferation of breast cancer cells and inhibits the anti-proliferative activity of anti-hormones. Endocr Relat Cancer 2006;13:905-19. [PubMed: 16954439]

34. Davis, DWHJ.; Desai, J.; George, S.; DePrimo, SE.; Bello, CL.; Baum, CM.; Demetri, GD. Correlation of receptor tyrosine kinase activity and apoptosis with response to sunitinib treatment in patients with gastrointestinal stromal tumor. EORTC-NCI-AACR International Conference on Molecular Targets and Cancer Therapeutics; 200610 November 2006; Prague, Czech Republic. \#57

35. Gibson MK, Li Y, Murphy B, Hussain MH, DeConti RC, Ensley J, et al. Randomized phase III evaluation of cisplatin plus fluorouracil versus cisplatin plus paclitaxel in advanced head and neck cancer (E1395): an intergroup trial of the Eastern Cooperative Oncology Group. J Clin Oncol 2005;23:3562-7. [PubMed: 15908667]

36. Stewart, S.; Cohen, EEW.; Licitra, L.; Van Herpen, CML.; Khorprasert, C.; Soulieres, D.; Vodvarka, P.; Rischin, D.; Garin, AM.; Hirsch, FR.; Ghiorghiu, S.; Hargreaves, L.; Speake, G.; Armour, A.; Vokes, EE. A Phase III randomized parallel-group study of gefitinib (IRESSA) versus methotrexate (IMEX) in patients with recurrent squamous cell carcinoma of the head and neck. American Association for Cancer Research; 2007 April 14-18; Los Angeles, CA. 2007. \#3522

37. Choong, NWHD.; Cohen, EEW.; Stenson, KM.; Blair, EA.; Dekker, A.; Williams, R.; Karrison, TG.; Vokes, EE. Randomized phase II study of concomitant chemoradiotherapy with 5-fluorouracilhydroxyurea (FHX) compared to FHX and bevazicumab (BFHX) in intermediate stage head and neck cancer (HNC). American Society of Clinical Oncology; 2007 June 1-5; Chicago, IL. 2007. \#6034

38. Kies, MSGM.; Kim, SW.; Savvides, P.; Blumenschein, GR.; Worden, F.; Chen, H.; Grandis, JR.; Argiris, AE. Cetuximab (C) and bevacizumab (B) in patients with recurrent or metastatic head and neck squamous cell carcinoma (SCCHN): An interim analysis. Annual Meeting American Society of Clinical Oncology; Chicago, IL. \#6072 


\section{Phase I}

$5 \mathrm{mg} / \mathrm{kg}: \mathrm{n}=4(1 \mathrm{NE})$

$10 \mathrm{mg} / \mathrm{kg}: \mathrm{n}=3$

$15 \mathrm{mg} / \mathrm{kg}: \mathrm{n}=3$ (included in phase II evaluation)

\section{Phase II}

$15 \mathrm{mg} / \mathrm{kg}: \mathrm{n}=44$ (1 NE)

(first 3 patients also used in MTD determination)

$\mathrm{N}=3+44-1=46$ evaluable patients per study design

2 additional patients accrued

$\mathrm{N}=46+2=48$ evaluable phase II patients

Figure 1.

Study flow diagram. $\mathrm{NE}=$ non-evaluable, $\mathrm{MTD}=$ maximum tolerable dose . 
A

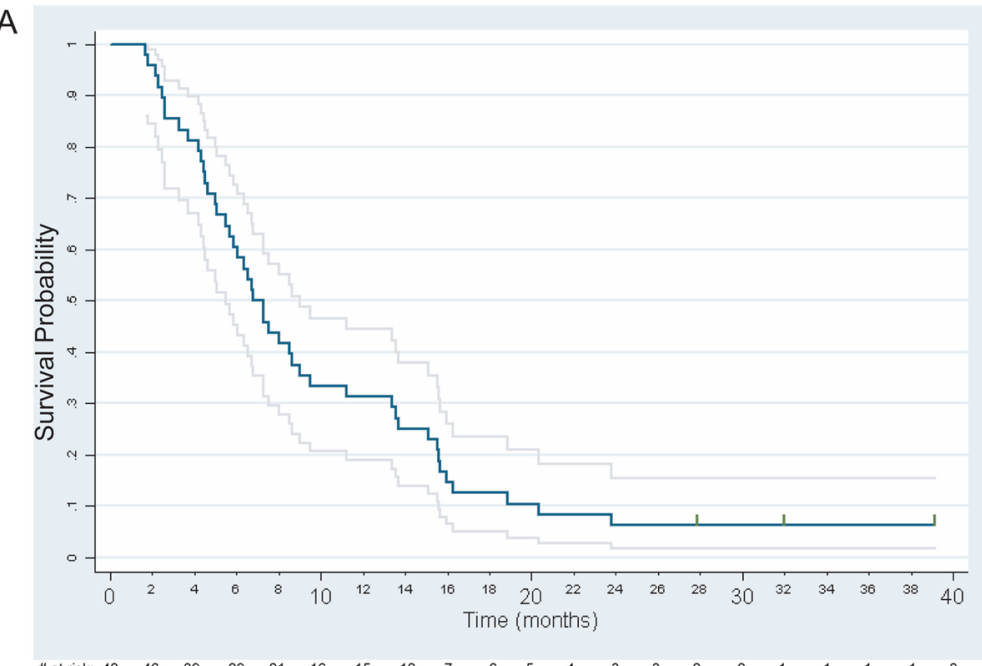

B

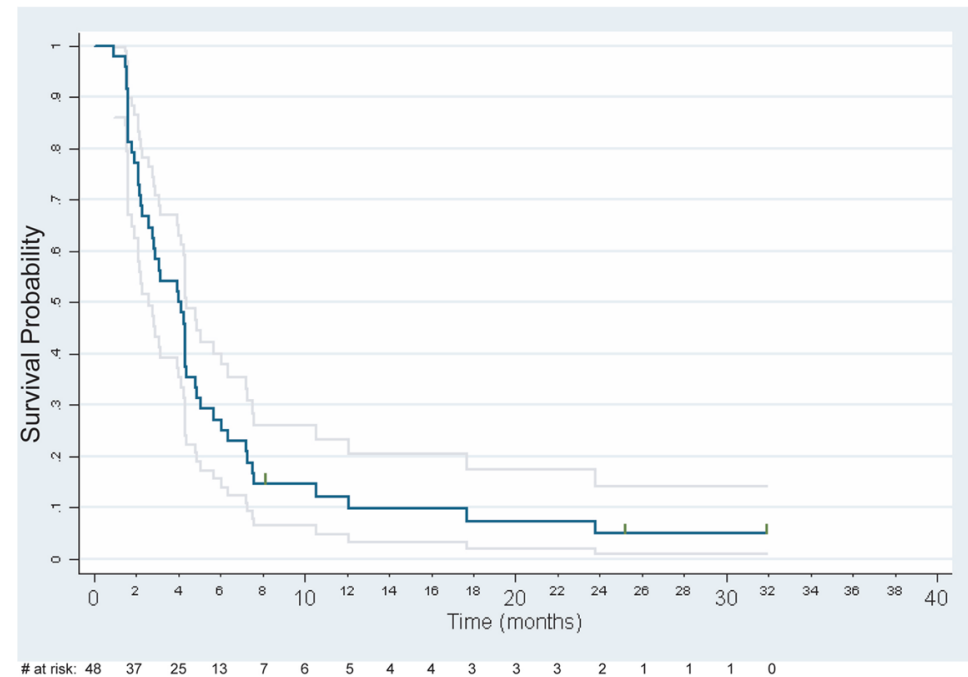

Figure 2.

(A) Overall survival ( $n=48$ ). (B) Progression-free survival ( $n=48$ ). Grey lines indicate $95 \%$ pointwise confidence intervals. Vertical tics denote censored observations. 
A

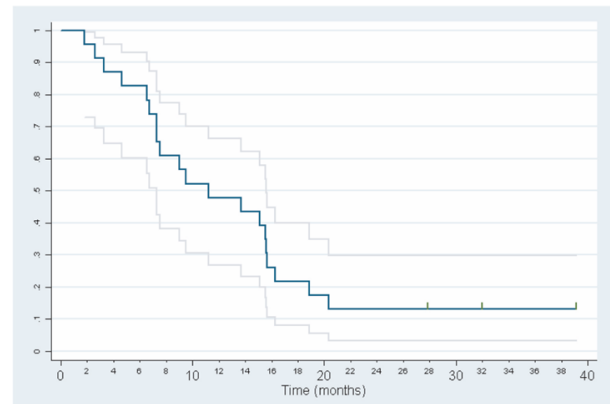

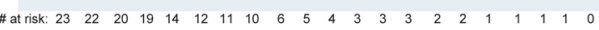

C

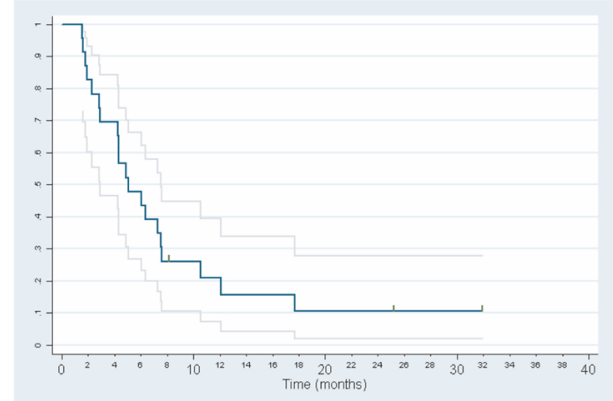

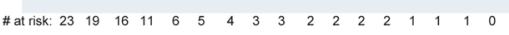

B

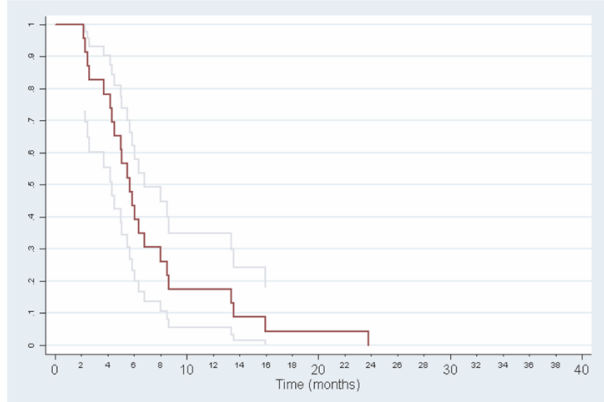

\# at risk: $23 \quad 23 \begin{array}{llllllllllll}18 & 10 & 7 & 4 & 4 & 2 & 1 & 1 & 1 & 1 & 0\end{array}$

$\mathrm{D}$

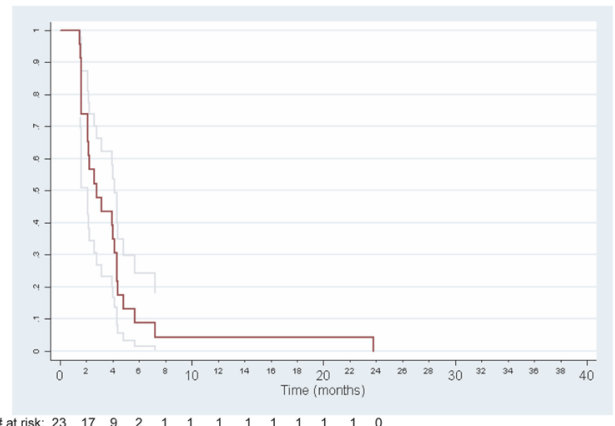

Figure 3.

(A) Overall survival in first-line patients $(n=23)$. (B) Overall survival in second-line patients $(n=23)$. (C) Progression-free survival in first-line patients $(n=23)$. (D) Progression-free survival in second-line patients $(n=23)$. Grey lines indicate $95 \%$ pointwise confidence intervals. Vertical tics denote censored observations. 

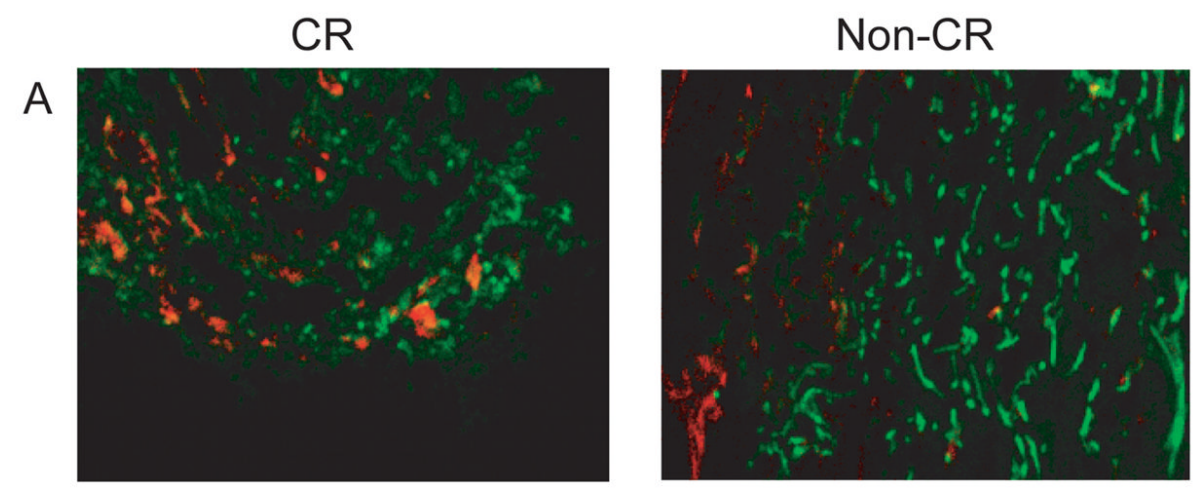

B
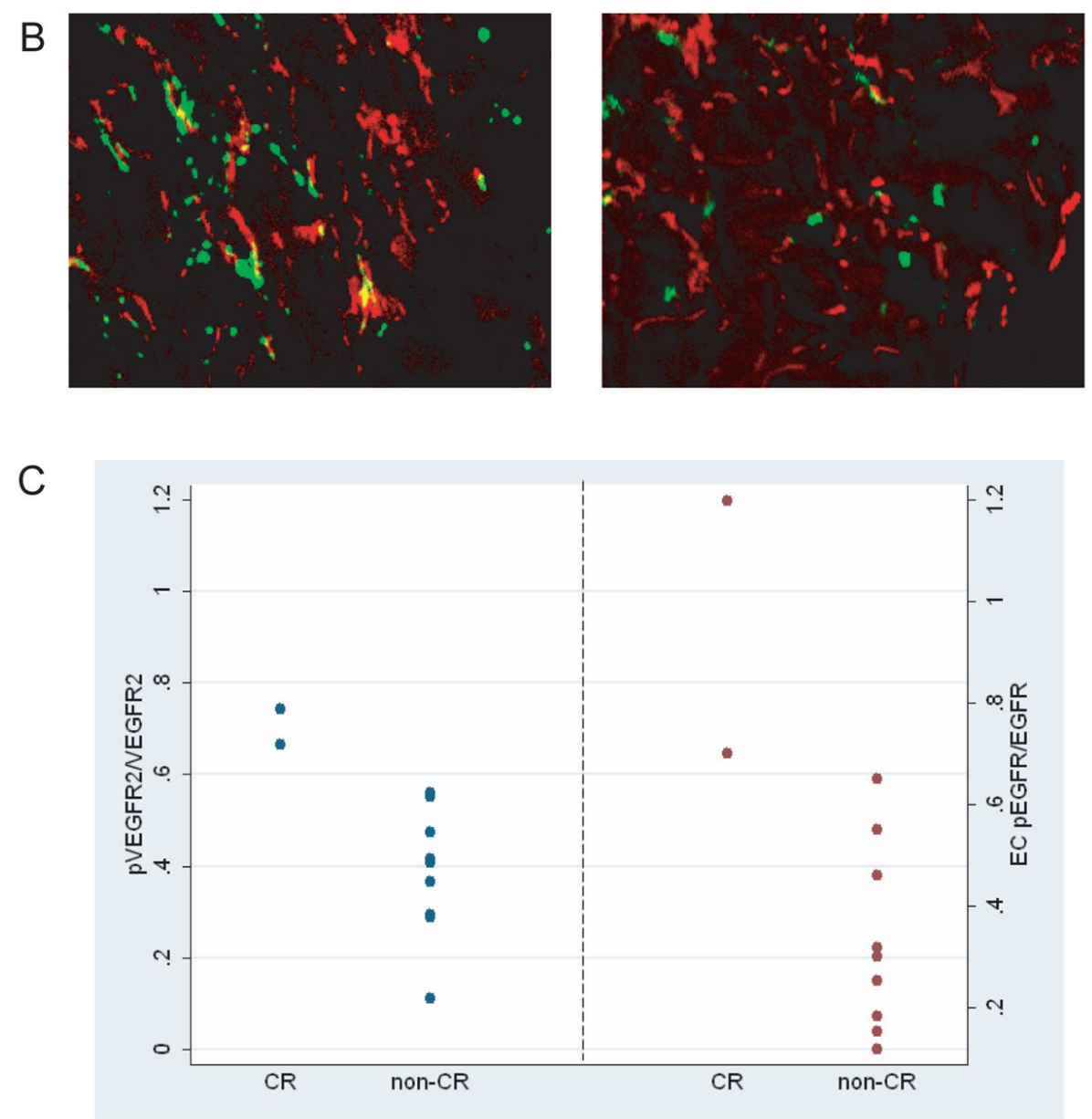

Figure 4.

(A) Representative laser scanned images show high expression of phosphorylated VEGFR2/ total VEGFR2 in CR compared to non-CR patients (pVEGFR2 stained red, VEGFR2 stained green). (B) High expression of phosphorylated EGFR/total EGFR in endothelial cells in CR vs. non-CR patients (pEGFR stained green, CD31 stained red). (C) Pre-treatment mean fluorescent intensity (MFI) of pVEGFR2/VEGFR2 ( $\mathrm{p}=0.036)$ and EC pEGFR/EGFR $(\mathrm{p}=0.036)$ quantified by laser scanning cytometry in $\mathrm{CR}$ vs. non-CR patients. 
A

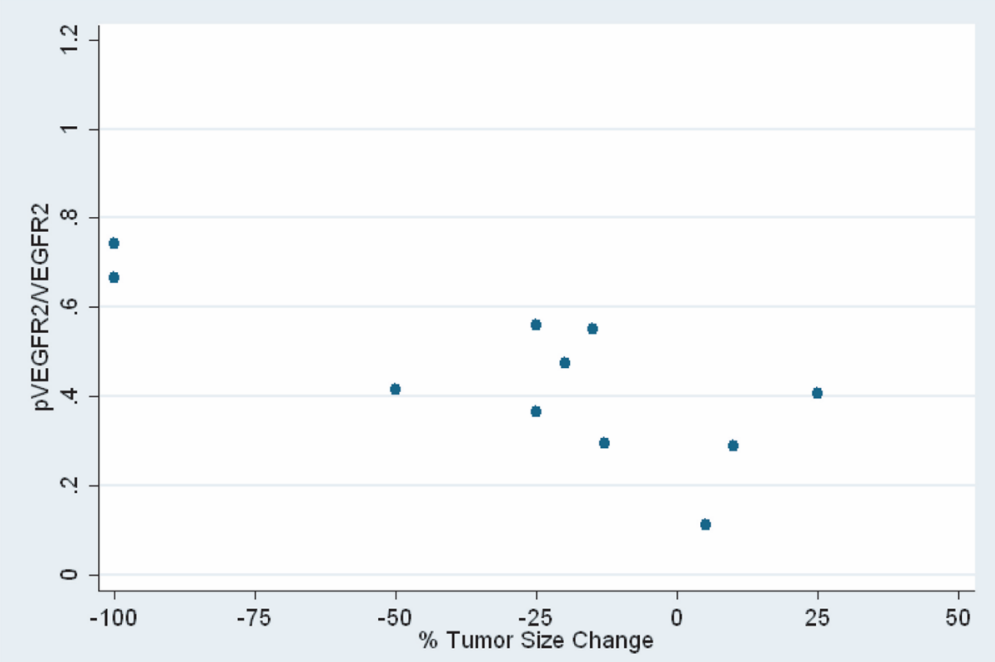

B

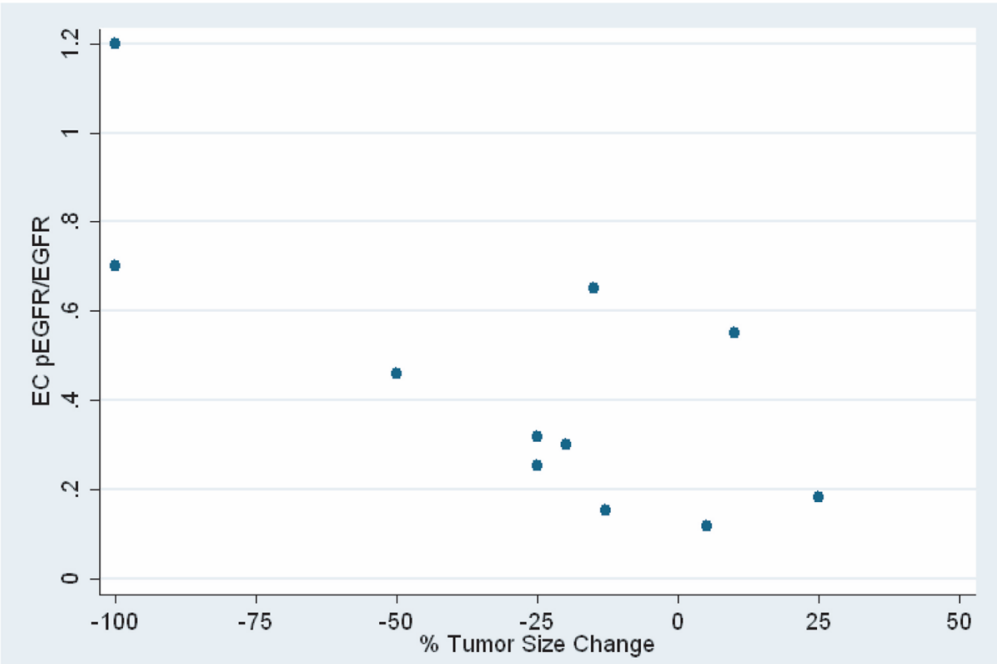

Figure 5.

Correlation between (A) pVEGFR2/VEGFR2 ( $\mathrm{p}=0.007)$ and (B) EC pEGFR/EGFR ( $\mathrm{p}=0.008)$ ratios and maximal reduction in tumor size $(\mathrm{n}=11)$. Complete responses were scored as $-100 \%$ in tumor size change. 
A

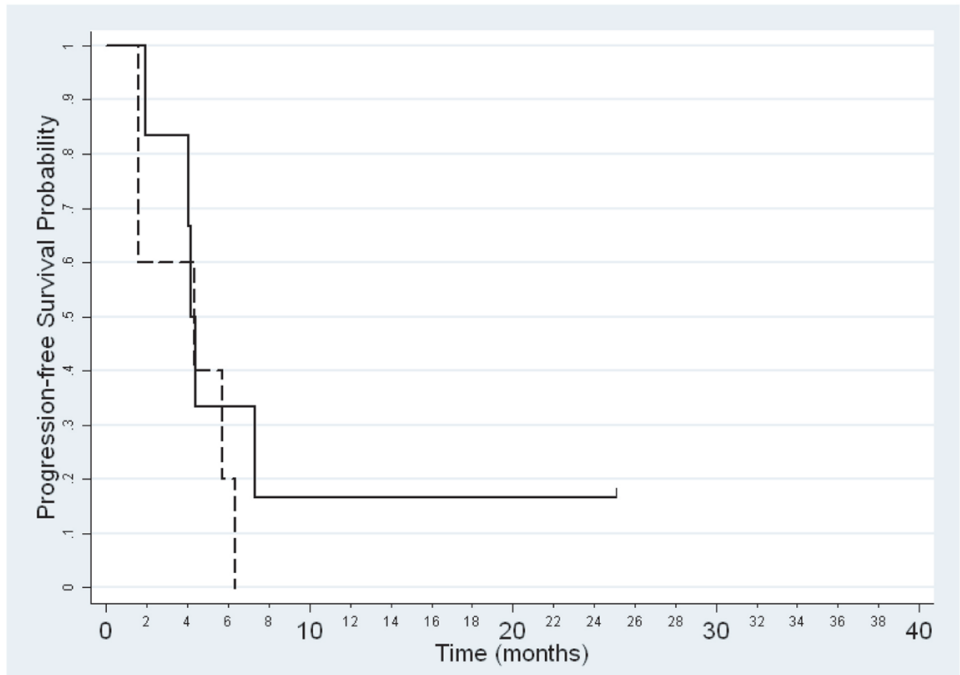

at risk: \begin{tabular}{rrrrrrrrrrrrrrr}
6 & 5 & 5 & 2 & 1 & 1 & 1 & 1 & 1 & 1 & 1 & 1 & 1 & 0 & $\begin{array}{c}\text { (solid line) } \\
5\end{array}$ \\
\hline & 3 & 1 & 0 & & & & & & & & & & \\
(dotted line)
\end{tabular}

B

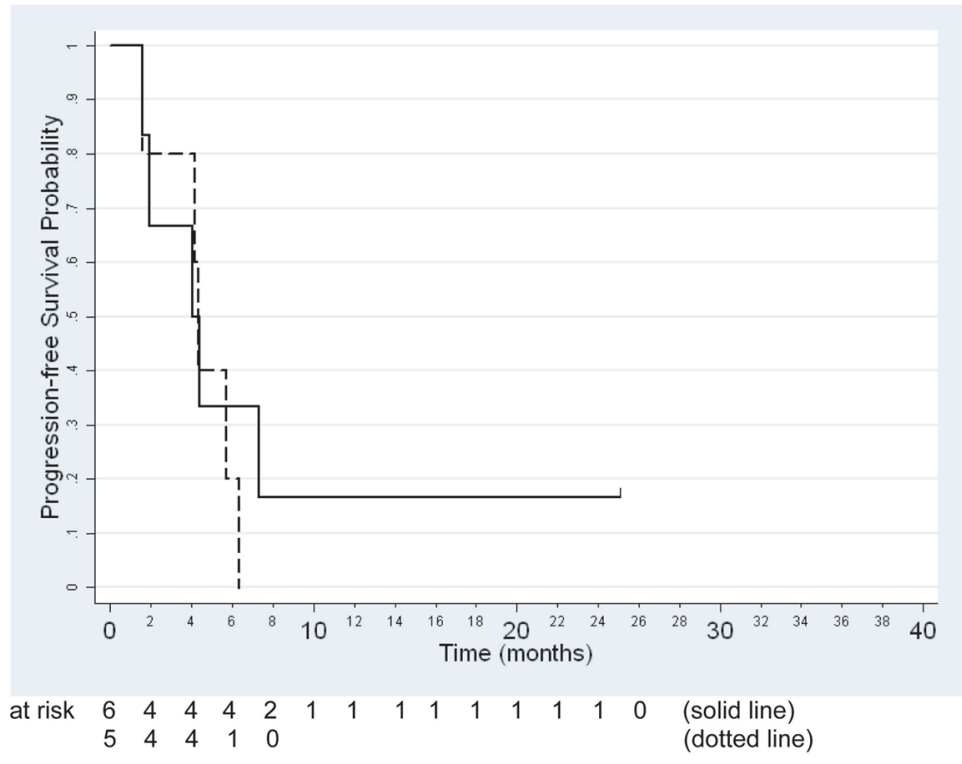

Figure 6.

Kaplan-Meier curves for the association between progression-free survival and (A) pVEGFR2/ VEGFR2 ( $\mathrm{p}=0.32$ ) or (B) EC pEGFR/EGFR ( $\mathrm{p}=0.12)$ ratios. Solid line represents subjects with a respective ratio at or above the median $(n=6)$. Dotted line represents subjects with a respective ratio below the median $(\mathrm{n}=5)$. 


\section{Table 1}

Clinical and Demographic Data for all Patients $(n=56)$

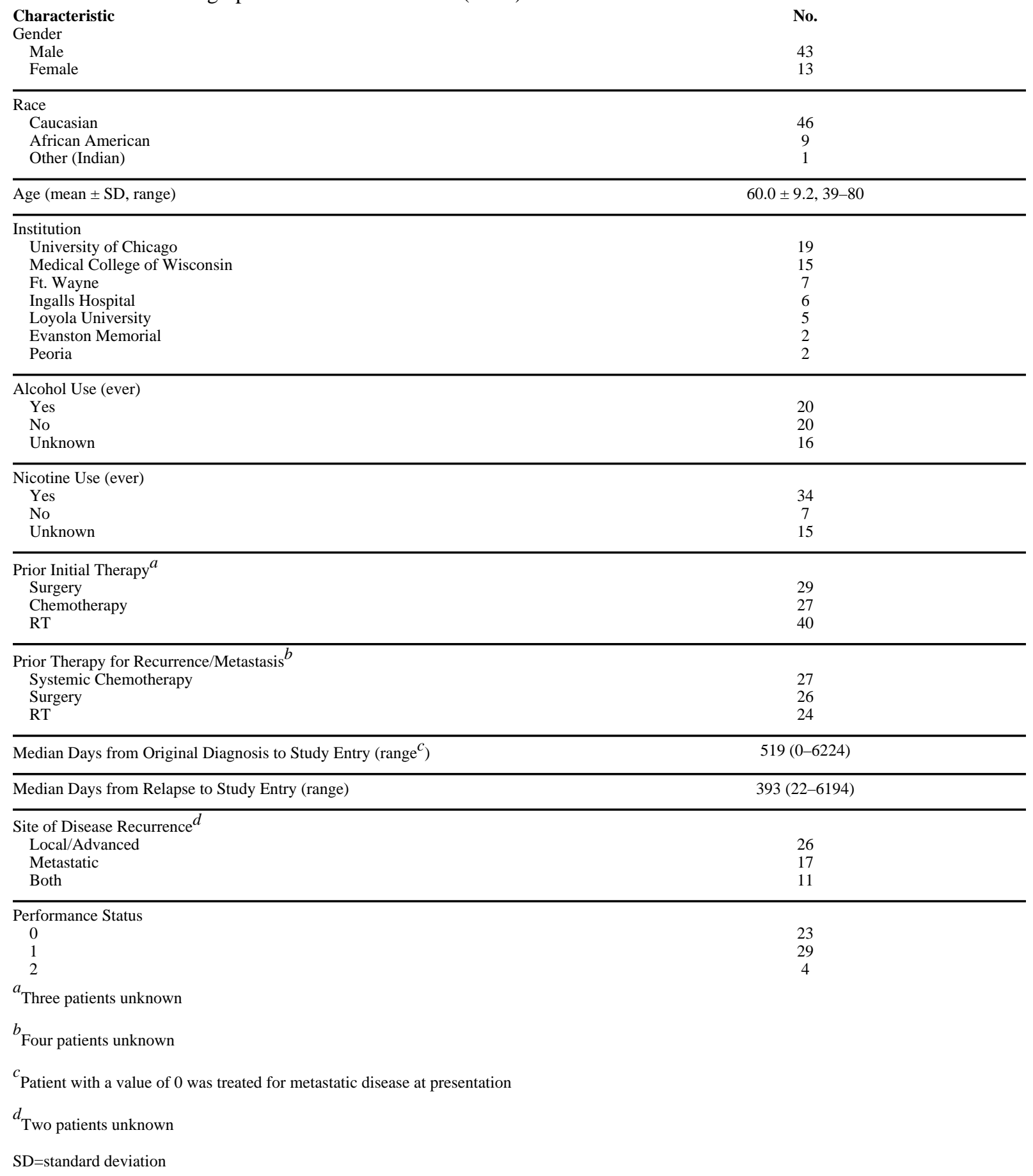




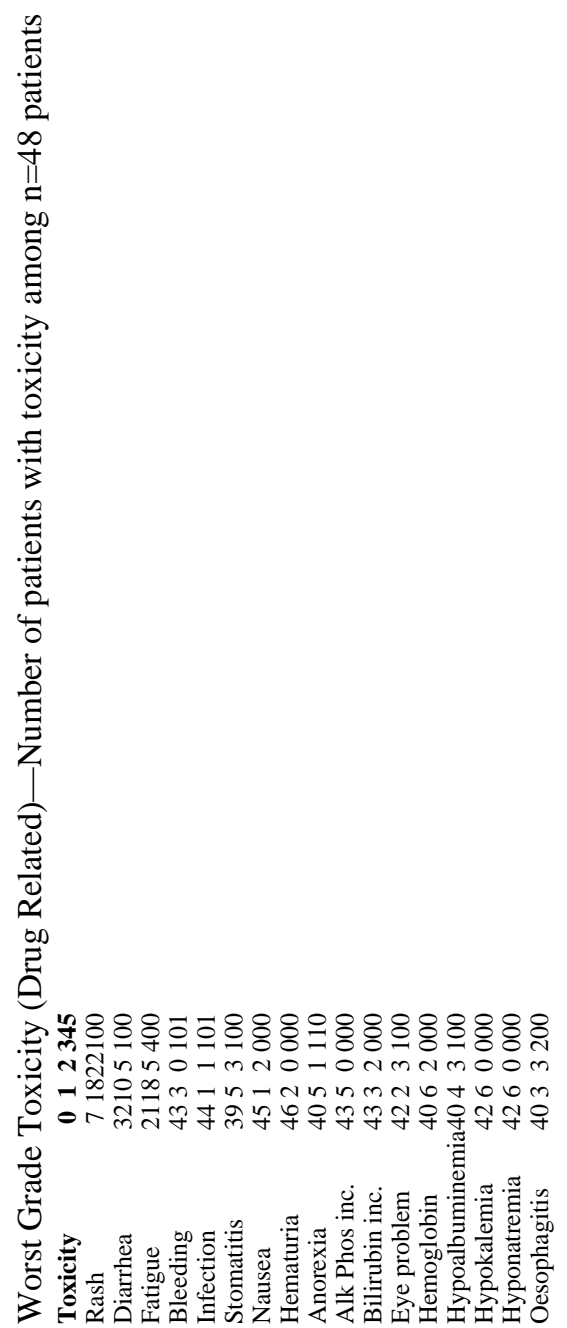

Lancet Oncol. Author manuscript; available in PMC 2010 March 1. 


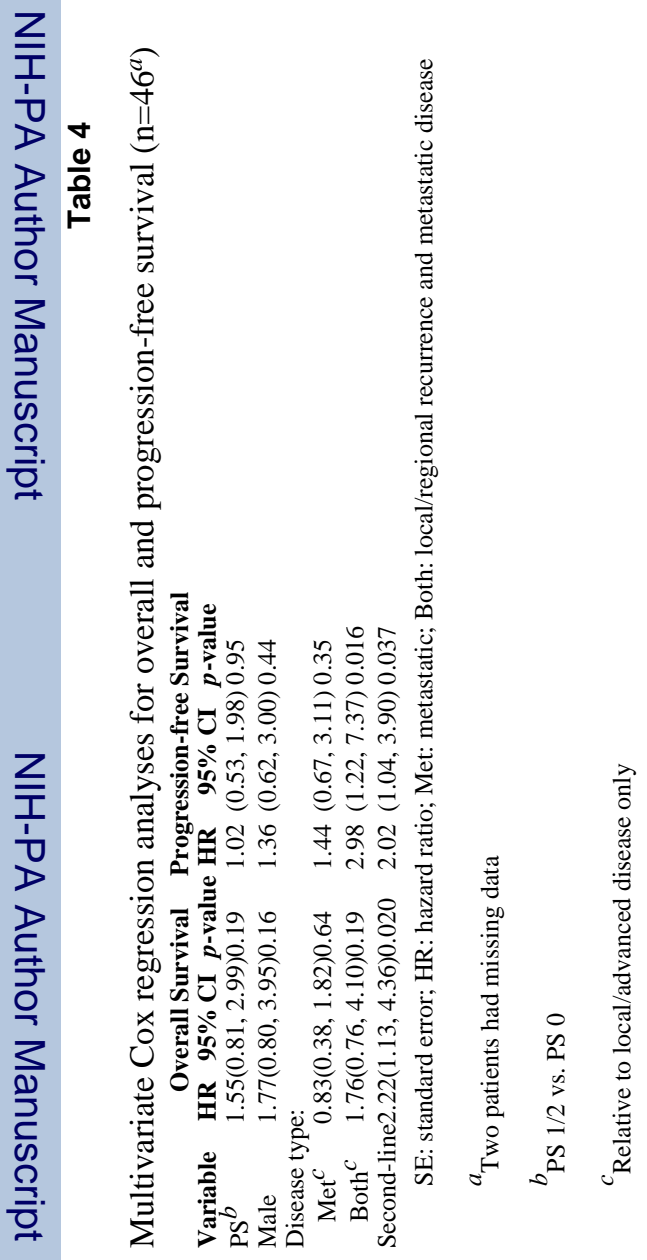




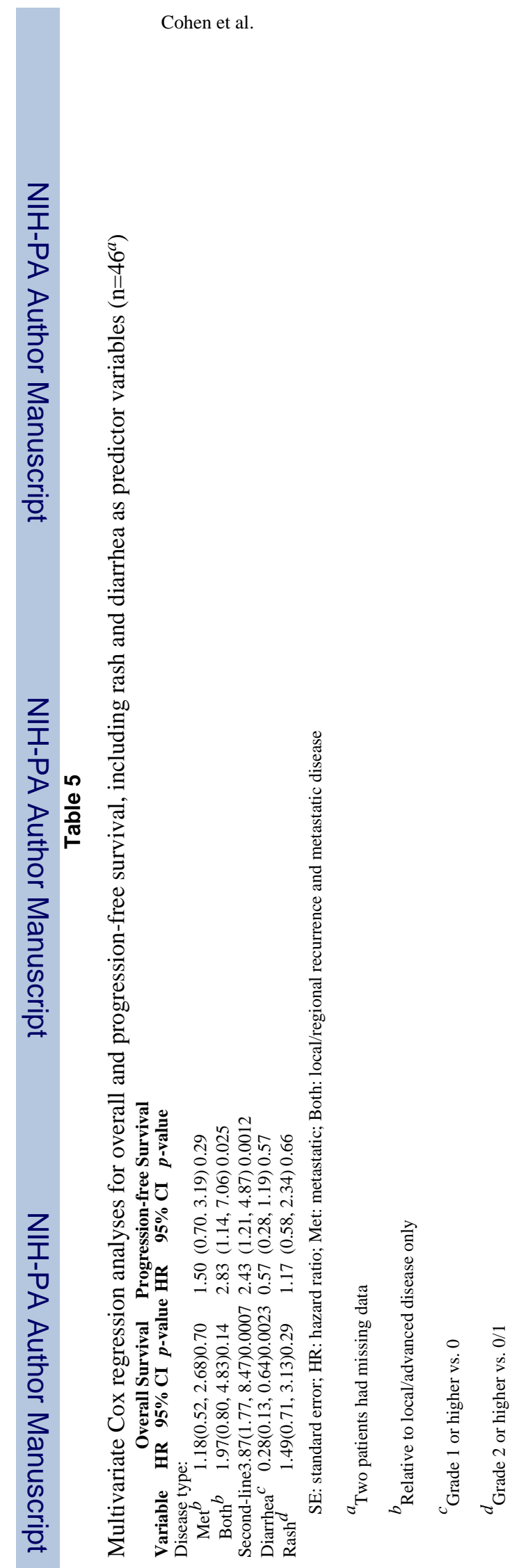

Page 22

Lancet Oncol. Author manuscript; available in PMC 2010 March 1. 


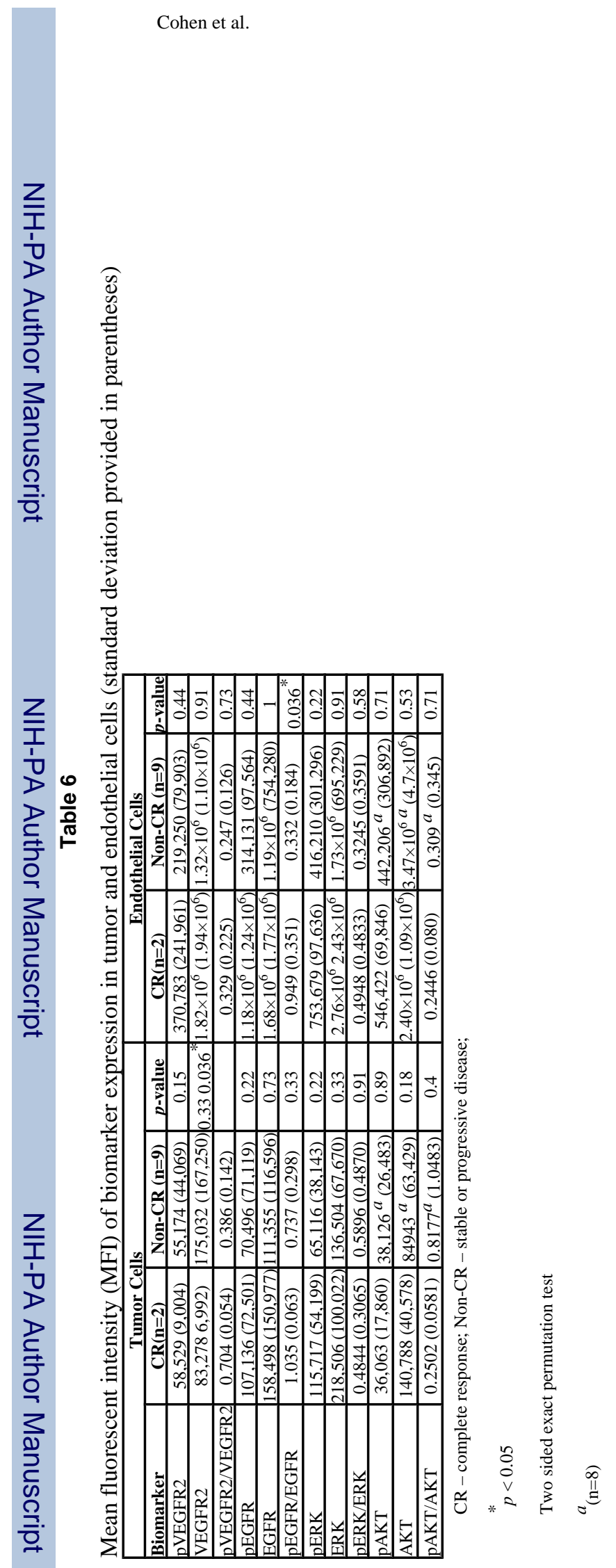

Page 23 